University of Nebraska - Lincoln

DigitalCommons@University of Nebraska - Lincoln

Faculty Publications: Materials Research

Science and Engineering Center

Materials Research Science and Engineering

Center

2007

\title{
Pairwise cobalt doping of boron carbides with cobaltocene
}

\author{
A. Yu. Ignatov \\ Center for Advanced Microstructures and Devices, Louisiana State University, 6980 Jefferson Highway, \\ Baton Rouge, Louisiana \\ Yaroslav B. Losovyj \\ Louisiana State University at Baton Rouge, ylozovyy@indiana.edu \\ L. Carlson \\ Air Force Institute of Technology, 2950 Hobson Way, Wright Patterson Air Force Base, Ohio 45433-7765, \\ USA \\ D. LaGraffe \\ Air Force Institute of Technology, 2950 Hobson Way, Wright Patterson Air Force Base, Ohio 45433-7765, \\ USA \\ Jennifer I. Brand \\ University of Nebraska-Lincoln, jbrand1@unl.edu \\ See next page for additional authors
}

Follow this and additional works at: https://digitalcommons.unl.edu/mrsecfacpubs

Part of the Materials Science and Engineering Commons

Ignatov, A. Yu.; Losovyj, Yaroslav B.; Carlson, L.; LaGraffe, D.; Brand, Jennifer I.; and Dowben, Peter A., "Pairwise cobalt doping of boron carbides with cobaltocene" (2007). Faculty Publications: Materials Research Science and Engineering Center. 68.

https://digitalcommons.unl.edu/mrsecfacpubs/68

This Article is brought to you for free and open access by the Materials Research Science and Engineering Center at DigitalCommons@University of Nebraska - Lincoln. It has been accepted for inclusion in Faculty Publications: Materials Research Science and Engineering Center by an authorized administrator of DigitalCommons@University of Nebraska - Lincoln. 


\section{Authors}

A. Yu. Ignatov, Yaroslav B. Losovyj, L. Carlson, D. LaGraffe, Jennifer I. Brand, and Peter A. Dowben 


\title{
Pairwise cobalt doping of boron carbides with cobaltocene
}

\author{
A. Yu. Ignatov and Ya. B. Losovyj \\ Center for Advanced Microstructures and Devices, Louisiana State University, 6980 Jefferson Highway, \\ Baton Rouge, Louisiana 70806, USA
}

L. Carlson and D. LaGraffe

Air Force Institute of Technology, 2950 Hobson Way, Wright Patterson Air Force Base, Ohio 45433-7765, USA

\section{J. I. Brand \\ College of Engineering and Technology, N245 Walter Scott Engineering Center, 17th and Vine Streets, University of Nebraska-Lincoln, Lincoln, Nebraska 68588-0511, USA}

\begin{abstract}
P. A. Dowben ${ }^{\text {a) }}$
Department of Physics and Astronomy, Behlen Laboratory of Physics, University of Nebraska, P.O. Box 880111, Lincoln, Nebraska 68588-0111, USA and the Nebraska Center for Materials and Nanoscience, Behlen Laboratory of Physics, University of Nebraska, P.O. Box 880111, Lincoln, Nebraska 68588-0111, USA
\end{abstract}

(Received 1 June 2007; accepted 23 August 2007; published online 18 October 2007)

\begin{abstract}
We have performed Co $K$-edge x-ray absorption fine structure and x-ray absorption near edge structure measurements of Co-doped plasma enhanced chemical vapor phase deposition (PECVD) grown " $\mathrm{C}_{2} \mathrm{~B}_{10} \mathrm{H}_{x}$ " semiconducting boron carbides, using cobaltocene. Cobalt does not dope PECVD grown boron carbides as a random fragment of the cobaltocene source gas. The Co atoms are fivefold boron coordinated $(R=2.10 \pm 0.02 \AA)$ and are chemically bonded to the icosahedral cages of $\mathrm{B}_{10} \mathrm{CH}_{x}$ or $\mathrm{B}_{9} \mathrm{C}_{2} \mathrm{H}_{y}$. Pairwise $\mathrm{Co}$ doping occurs, with the cobalt atoms favoring sites some 5.28 $\pm 0.02 \AA$ apart. (C) 2007 American Institute of Physics. [DOI: 10.1063/1.2799053]
\end{abstract}

\section{INTRODUCTION}

The ability to generate semiconducting grades of boron carbide films by plasma enhanced chemical vapor phase deposition (PECVD) of carboranes permits the development of corrosion resistant, high temperature devices with many applications including neutron detection. ${ }^{1-7}$ These boron carbides, of approximate stoichiometry " $\mathrm{C}_{2} \mathrm{~B}_{10} \mathrm{H}_{x}$ " (where $x$ represents up to $\sim 5 \%$ molar fraction of hydrogen), exhibit a range of electronic properties (i.e., $p$ type or $n$ type) presumably as a result of differing polytypes. ${ }^{7,8}$ Successful $n$-type doping of the $\beta$-rhombohedral boron has been accomplished with dopants such as iron, ${ }^{9-13}$ vanadium, ${ }^{12,13}$ chromium, ${ }^{12,13}$ nickel, ${ }^{13}$ while cobalt ${ }^{12,13}$ and zirconium, ${ }^{12}$ may be a $p$-type dopants. For the related boron carbides, nickel is certainly a $n$-type dopant, ${ }^{14-17}$ while cobalt may or may not $^{18}$ be a $p$-type dopant of the boron carbides. Dopants such as $\mathrm{Mg},{ }^{19}$ $\mathrm{Si}^{19}{ }^{19}$ and $\mathrm{Hg}$ (Ref. 20) are not $n$-type dopants for boron carbide either, if they are even dopants in the conventional sense at all. Phosphorus, like cobalt, also may ${ }^{21}$ or may not ${ }^{19}$ be a $n$-type dopant of boron carbide. If cobalt is a successful dopant two questions surface, beyond those related to the question of the majority carrier introduced by cobalt doping: is the doping random, i.e., dilute, ${ }^{22,23}$ or do the dopants cluster as has been observed for cobalt dopants in some oxide dielectrics? ${ }^{24}$

One possible route for cobalt doping of $\mathrm{C}_{2} \mathrm{~B}_{10} \mathrm{H}_{x}$ semiconducting boron carbides is to include the cobalt metallocene or cobaltocene $\mathrm{Co}\left(\mathrm{C}_{5} \mathrm{H}_{5}\right)_{2}$ (schematically shown in

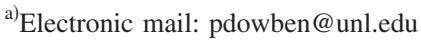

Fig. 1, left) simultaneously with a carborane source molecule, such as 1,7-closo-dicarbadodecaborane, sometimes known as metacarborane, during PECVD. ${ }^{18}$ This approach is similar to the successful nickel doping of boron carbides using nickelocene. Nickel, via nickelocene, was successfully introduced as a dopant in semiconducting boron carbides grown by PECVD from orthocarborane (closo-1,2-dicarbadodecaborane). ${ }^{14-17}$ Cobaltocene has been shown to successfully dope $\mathrm{SnS}_{2}{ }^{25,26}$ Here we explore the site location of the cobalt in $\mathrm{C}_{2} \mathrm{~B}_{10} \mathrm{H}_{x}$ semiconducting boron carbide.

\section{EXPERIMENTAL}

The doped boron carbide films used for the x-ray absorption near edge structure (XANES) and $\mathrm{x}$-ray absorption fine structure (EXAFS) measurements were produced using PECVD with only metacarborane, cobaltocene and argon as the plasma reactor gases, as previously described. ${ }^{18}$ This PECVD approach is well established and has been successful in the fabrication of both heterojunction ${ }^{1-4,16,17,21}$ and homo-
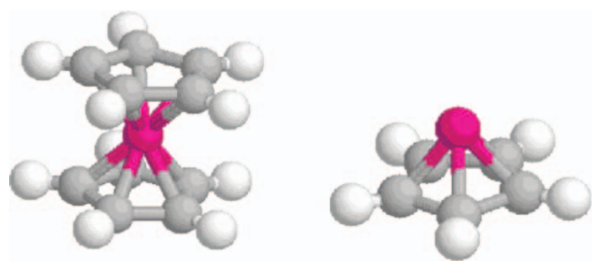

FIG. 1. (Color) Cobaltocene molecule $\mathrm{Co}\left(\mathrm{C}_{5} \mathrm{H}_{5}\right)_{2}$ and the cyclopentadienal cobalt fragment are shown. Color code for this and all other structures throughout this paper is the following: Co: red, B: green, C: gray, H: white. 


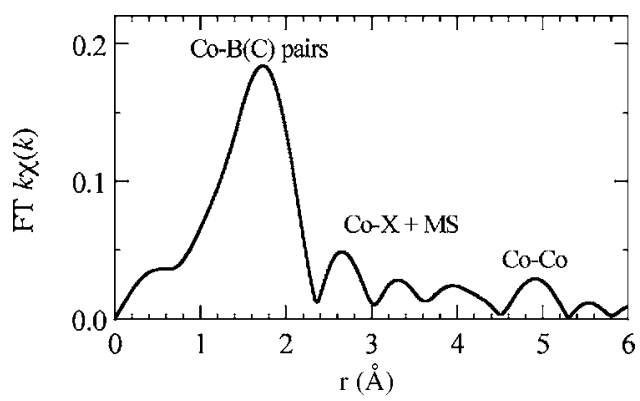

FIG. 2. A magnitude of the Fourier transform of $k \chi(k)$ about the Co-based species in the PECVD grown boron carbide. The data are transformed for data taken from between 3.56 and $11.0 \AA^{-1}$. The major peak is due to contribution of $\mathrm{Co}-\mathrm{B}(\mathrm{C})$ atomic pairs. The peak at $\sim 5 \AA$ is associated with Co-Co pairs.

junction diodes ${ }^{14,15,18}$ of boron carbide as well as diodes made from two polytypes of boron carbide..$^{5-7,21}$

$\mathrm{X}$-ray photoemission spectroscopy (XPS) confirmed that cobalt is indeed incorporated in $\mathrm{C}_{2} \mathrm{~B}_{10} \mathrm{H}_{x}$ boron carbide films after cobaltocene decomposition, in films formed from both metacarborane and cobaltocene decompositions. From the relative XPS intensities, we estimate that there is only about $0.5 \%-1.5 \%$ cobalt (or less) in these $\mathrm{C}_{2} \mathrm{~B}_{10} \mathrm{H}_{x}$ films. The estimate may be higher than is the bulk concentration due to surface segregation and given that XPS is surface sensitive. ${ }^{18}$

Co $K$-edge XANES and EXAFS spectra were collected at the DCM beamline at the Center for Microstructures and Devices (CAMD). Monochromatic light was obtained by using a double crystal monochromator of Lemonnier type, ${ }^{27}$ equipped with a $\mathrm{Ge}(220)$ crystal pair. The estimated energy resolution was approximately $2 \mathrm{eV}$. The higher energy harmonics were suppressed by detuning the second crystal of the monochromator on its rocking curve to deliver $\sim 60 \%$ of maximum intensity at $1 \mathrm{keV}$ above the edge. Spectra were acquired in the fluorescent yield mode, using a Ge detector (Canberra) with an energy resolution of $\sim 300 \mathrm{eV}$. Due to the low Co concentrations, the data were not corrected for selfabsorption. Two to five scans were collected to ensure reproducibility of the experimental data. The absolute energy scale was calibrated by assigning $E=7709 \mathrm{eV}$ to the first inflection point of the spectra taken from a Co metal foil. The EXAFS data were reduced according to the standard procedure. ${ }^{28} \mathrm{~A}$ typical $\chi(k)$ spectrum weighted by $k$ demonstrates good data quality up to $\sim 11 \AA^{-1}$.

\section{EXTENDED ABSORPTION FINE STRUCTURE (EXAFS)}

A magnitude of the Fourier transformed $\chi(k)$ EXAFS function weighted with $k$ is shown in Fig. 2. This Fourier transform is not precisely the pair radial distribution function but does provide an indication of the radial spacings of atoms in the vicinity of cobalt in the PECVD grown materials (with only metacarborane, cobaltocene, and argon as the plasma reactor gases, as described above). Since the structure of the Co-doped boron carbides is unknown, the assignment of peaks in Fig. 2 is not trivial. As will be shown below, a major peak at $\sim 1.8 \AA$ is due to single-scattering contribution of $\mathrm{Co}-\mathrm{B}(\mathrm{C})$ atomic pairs. Peaks between 2.5 and $4.5 \AA$ are

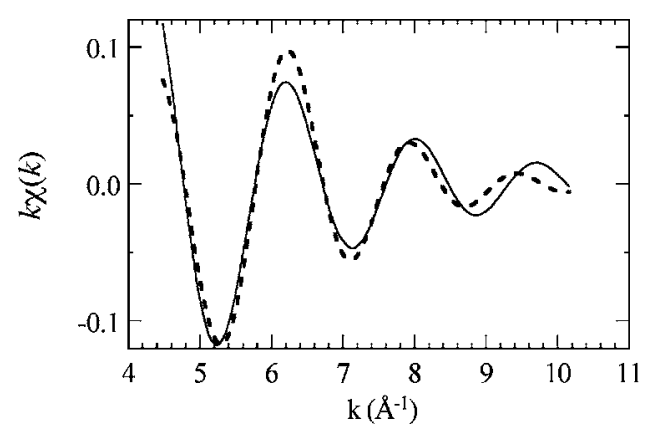

FIG. 3. Comparison of the Fourier filtered data (dashed line) with model involving two $\mathrm{Co}-\mathrm{B}(\mathrm{C})$ pairs (solid line). Parameters of the model are given in Table I.

due to $\mathrm{Co}-X$ pairs (where $X$ could be any of light scatters, such as $\mathrm{B}, \mathrm{C}, \mathrm{N}$, and $\mathrm{O}$ ) and due to multiple scattering contributions. Composition information, PECVD preparation conditions, and synchrotron photoemission results tend to eliminate any scatters other than boron and carbon. The peak at $\sim 5 \AA$ is associated with the Co-Co pairs. The absence of peaks at $R>8 \AA$ indicates lack of long-range order periodicity. Indeed, the sample does not diffract elastically, and, therefore, is amorphous or at best quasiperiodic.

Contribution to the EXAFS from the major peak was isolated by a transformation to the $k$ space over the range of $0.9-2.3 \AA$. The resulting spectrum was fitted over the range of 4.5-10.5 $\AA^{-1}$ in terms of two-shell model, allowing the interatomic distances, coordination numbers, and DebyeWaller (vibrational) factors to vary freely while constraining energy shifts, $d E_{1}=d E_{2}$. Theoretical amplitudes and phase shifts were obtained from FEFF-3 (an atomic pair code) as the first iteration for the unknown structure and further improved by FEFF-8.2 (Ref. 29) as a three dimensional (3D) structure gained from analysis of the XANES (Sec. IV). A good quality fit was achieved (Fig. 3) for both B and C placed as the nearest neighbor atoms to cobalt. Structural parameters derived from the nonlinear fit are summarized in Table I. For the Co-Co contribution to the EXAFS, a good fit was obtained for one cobalt neighbor at $5.28 \pm 0.02 \AA$, as indicated in Fig. 4. Therefore, Co forms a dilute, but not random dopant, of boron carbide.

While our EXAFS data provide important structural parameters about the Co atoms in the amorphous phase, more information is needed to assign the cobalt binding sites. For this we employed first principles simulations of XANES to gain information about local 3D structure about Co atoms in boron carbide.

TABLE I. Structural parameters of Co-based species derived from the nonlinear EXAFS fit. $S_{0}{ }^{2}=0.85$. For the ranges of fit of $4.5-10.5 \AA^{-1}$ in the $k$ space and $0.9-2.3 \AA$ in the $r$ space, the allowed number of fitting parameters is 7 . Typical accuracy for DW factor is $\sim 15 \%$.

\begin{tabular}{lccc}
\hline \hline & & $\begin{array}{c}\text { Coordination } \\
\text { number }\end{array}$ & Debye-Waller $\left(\AA^{2}\right)$ \\
\hline Atomic pairs & Interatomic distance $(\AA)$ & $2 \pm 1$ & 0.0034 \\
Co-B(C) & $1.96 \pm 0.02$ & $6 \pm 2$ & 0.0062 \\
Co-B(C) & $2.10 \pm 0.02$ & $1 \pm 0.2$ & 0.0047 \\
Co-Co & $5.28 \pm 0.02$ & & \\
\hline \hline
\end{tabular}




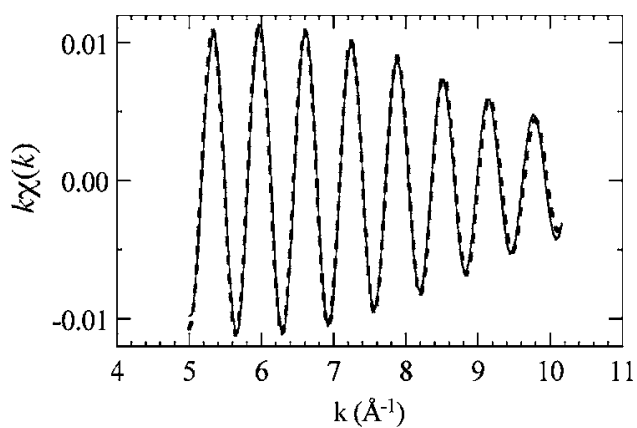

FIG. 4. Comparison of the Fourier filtered data (dashed line) with model involving Co-Co pairs (solid line). Parameters of the model are given in Table I. BFT and fit range are 4.6-5.4 $\AA$ (squire window) and $5.0-10.2 \AA^{-1}$, respectively.

\section{X-RAY ABSORPTION NEAR EDGE STRUCTURE (XANES)}

The normalized Co $K$-edge XANES of Co-doped boron carbide, compared to the Co $K$-edge XANES from a Co metal foil, is shown in Fig. 5. Strong hybridization between cobalt and the inorganic host matrix is evident: the Co-doped boron carbide grown by PECVD exhibits a surprisingly strong pre-edge feature $(\sim 20 \%-30 \%$ of intensity obtained from the normalized XANES from a Co foil). Pre-edge structures for cobalt (and other $3 d$ transition metals) are usually associated with transitions to unoccupied Co $4 p$ states hybridized with unoccupied $3 d$ states. The pre-edge structure is mostly due to transitions to empty states formed by hybridization of on-site Co $4 p$ with off-site states of not too distant neighboring atoms (possibly even the $d$ states of not too distant Co atoms, paired as noted above).

XANES is sensitive to both electronic and local structures. The latter sensitivity is employed to "refine" the structure about the Co atoms. Unlike EXAFS, the present stateof-the-art XANES theory is not developed enough to perform direct fits to the experimental XANES data. We will

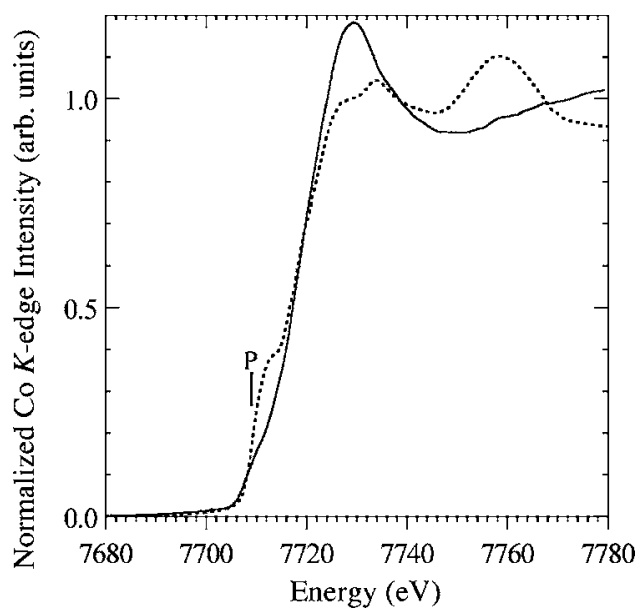

FIG. 5. Normalized Co $K$-edge XANES spectra of Co-doped boron carbide (solid line) and Co metal foil (dashed line). Both spectra after background subtraction were normalized to 1.0 at $60 \mathrm{eV}$ above the absorption threshold. Note distinctive features at the absorption edge of the Co-doped boron carbide, signaling on strong hybridization between cobalt and the inorganic host matrix. Origin of the features emerges from $a b$ initio XANES calculations as described in the text.

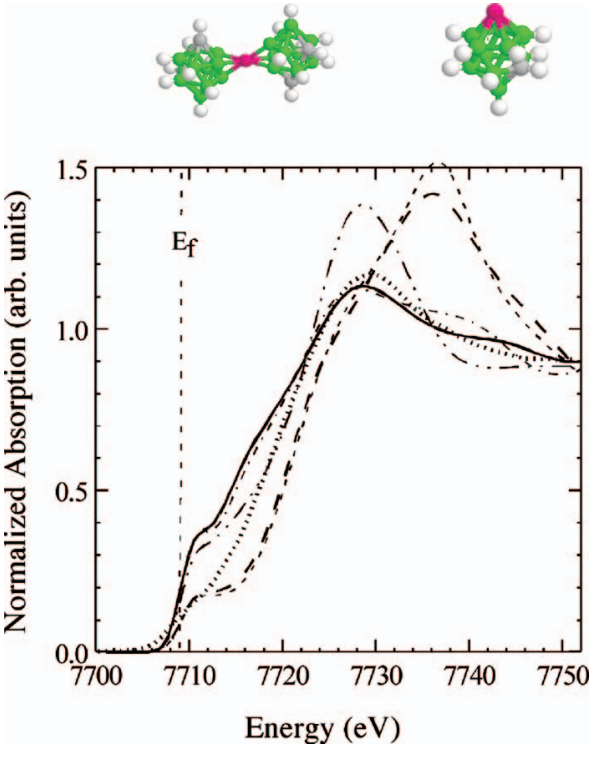

FIG. 6. (Color) Experimental Co $K$-edge XANES (dots) is compared with five calculated XANES spectra due to representative structures: model curve representative of cobaltocene (left panel of Fig. 1) is shown by long-dashed line. A model curve based on a hypothetical dehydrogenated cobaltocene, though keeping a Co-C distance of $1.96 \AA$, is show by short-dashed line. A model XANES curve based on a cyclopentadienyl cobalt with $\mathrm{Co}-\mathrm{C}$ distance relaxed to $2.1 \AA$ A (right panel of Fig. 1) is show by dot-dashed line. A model based on Co in the vicinity of two octahedra (top left panel of this figure) and a model where Co occupies the apical position within the cage (top right panel of this figure) give rise to the XANES shown by double dot-dashed and solid lines, respectively. All spectra are normalized to 1.0 at $60 \mathrm{eV}$ above absorption threshold. The vertical dashed line correspond estimated position of the Fermi energy relative to the core threshold. Note that a "half-open" structures where Co is fivefold C(B) coordinated are preferred in the fitting of the model calculations to experiment to models where Co atom is "squeezed" between two carbon pentagons or two icosahedral cages. N.B. XANES is not very sensitive to the hydrogen atoms: hydrogen location and stoichiometry cannot be reliably determined.

follow the common practice of reproducing major features and trend of changes in experimental spectra through model calculations. XANES simulations require knowledge of structure to assemble a cluster of atoms about absorption site. Even for clusters of average sizes, the total number of structural parameters far exceeds the plausible number of parameters that XANES computations can afford. Rather than provide $\{X, Y, Z\}$ for each atom in the cluster, different types of atomic arrangements, characterized by distinctive 3D group(s) of atoms, have been considered below. Radial spacing information from the Co $K$-edge EXAFS was used as a constraint in the XANES simulations.

To model the experimental Co $K$-edge XANES spectrum, the muffin-tin potentials were constructed for each specific cluster of atoms assembled, as described below. The x-ray absorption cross sections were calculated in the dipole approximation with a basis of $s, p, d$, and $f$ scattering states at each site. Two static limits, namely, fully relaxed $Z+1$ potential and unrelaxed $Z$ potential approximations, were considered. The fully relaxed potential brings about a rigid downward energy shift of $\sim 1 \mathrm{eV}$ and slightly increases the intensity of the peaks just above the absorption threshold. A modified DLXANES code, ${ }^{30}$ carrying out a direct inversion of the scattering matrix, was used. To compare the calculated spectra with experiment (Figs. 6-8), the former were convo- 


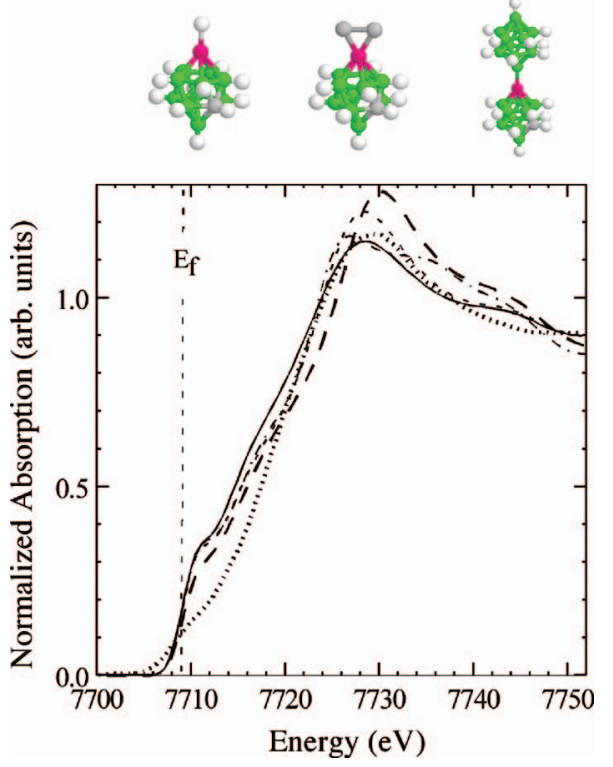

FIG. 7. (Color) The upper panel shows three representative capped model structures. Experimental Co $K$-edge XANES ("wide dots") is compared with computed XANES spectra due to the clusters shown. The left schematic: the half-open $\mathrm{Co}-\mathrm{B}_{10} \mathrm{CH}_{x}$ structure is capped with one hydrogen (a Co-H distance of $1.64 \AA$ is assumed) providing a model XANES illustrated by the solid line; central schematic: the structure is capped with two carbons (Co-C distance of $1.96 \AA$ to satisfy the EXAFS derived results), has a XANES illustrated by the long dashed line; right schematic: the structure is capped with $\mathrm{B}_{10} \mathrm{C}_{2} \mathrm{H}_{11}$ metacarborane cage, provides a XANES illustrated by the dot-dashed line. In addition, the short dashed line corresponds to the structure capped with a single $\mathrm{C}$ atom with the $\mathrm{Co}-\mathrm{C}$ distance of $1.96 \AA$ (similar to that shown in the left panel schematic).

luted with a Lorentz function. The broadening factor was taken as a sum of three constituents: core hole lifetime $(\sim 0.6 \mathrm{eV})$, instrumental resolution of $\sim 1.5 \mathrm{eV}$ (with the $\mathrm{Ge}$ (220) monochromator at the Co $K$-edge), and the energydependent photoelectron lifetime which was assumed to increase proportionally from zero at $E_{F}$ to $1 \mathrm{eV}$ at $60 \mathrm{eV}$ above.

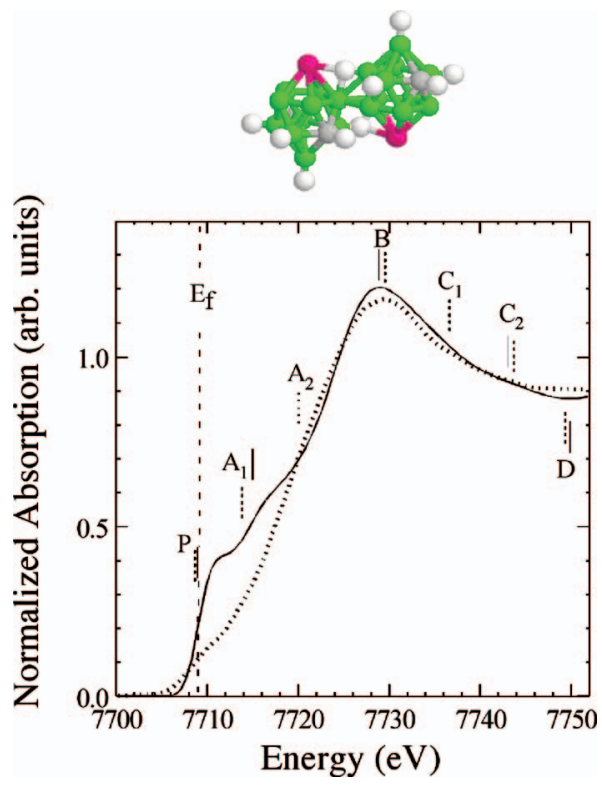

FIG. 8. (Color) Comparison of experimental Co $K$-edge XANES of Codoped boron carbide (dashed line) with our best ab initio XANES spectrum (solid line) corresponding to cluster of atoms shown in the top panel.
As we have noted above, EXAFS suggests a pairwise doping of the boron carbides, with $\mathrm{Co}-\mathrm{Co}$ interatomic distance of $\sim 5.28 \AA$ and coordination number of $\sim 1$. Both XANES and EXAFS are additive, meaning that total absorption cross section is a sum of partial contributions of distinctive sites,

$$
\mathrm{XANES}_{\mathrm{tot}}(E)=0.5\left[\mathrm{XANES}_{1}(E)+\mathrm{XANES}_{2}(E)\right]
$$

where $\mathrm{XANES}_{1}(E)$ and $\mathrm{XANES}_{2}(E)$ are contributions due to the $\mathrm{Co}(1)$ and $\mathrm{Co}(2)$ sites.

In considering the wide variety of XANES simulations undertaken, those that considered different types of single Co-site carborane or cobaltocene based clusters must be considered possible but incomplete. This is based on comparing spectroscopic signatures based from these cluster models with the experimental Co $K$-edge XANES used as a reference sample. In considering clusters formed from possible residual fragments of the two constituents used to produce Co-doped boron carbides, cobaltocene and carborane molecules, we found little agreement with experiment. The XANES of dehydrogenated cobaltocene (long dashed line in Fig. 6) and its fragment, less the hydrogen, shown in Fig. 1 (short dashed line), do not reproduce the experimental spectrum ("wide" dots). The XANES of cyclopentadienal cobalt (dot-dashed line), with the Co-C distanced allowed to relax to $2.1 \AA$ to satisfy the results derived from EXAFS, shows a somewhat better resemblance to the experimental data. No other clusters involving cobaltocene fragments produce a better match. Alternatively, Co could favor a site position in close proximity to the boron (carbon) atoms in the carborane cage (Co cannot be inside the icosahedral cage due to size constraints). Hydrogen is lost preferentially from an adjacent carbon and boron site in the decomposition process, ${ }^{31,32}$ so these exopolyhedral sites are clearly available as coordination sites for cobalt. The coordination number of $\sim 3$ is, however, too low to satisfy the EXAFS results unless the cobalt is located between two carborane cages (double dot dashed line in Fig. 6) or adopts an endopolyhedral position occupying an apical position within the cage (solid line). The latter certainly would give the cobalt a fivefold coordination to the nido-carborane $\mathrm{CB}_{11}$ cage similar to a number of known metalloboranes. ${ }^{33}$ In this case, there is a conversion of adjacent icosahedra by removal of a $\mathrm{B}, \mathrm{BH}, \mathrm{C}$, or $\mathrm{CH}$ vertex, followed by introduction of the $\left(\mathrm{C}_{5} \mathrm{H}_{5}\right)$ Co vertex. ${ }^{33,34}$ This should be a facile reaction. ${ }^{29}$ The preservation of the icosahedral cage in our semiconducting boron carbides is suggested by the correspondence between the dipole ${ }^{35}$ and the alignment of the chemical potential for the dehydrogenated boron carbide, ${ }^{6,7}$ as well as some structural studies. ${ }^{8}$

The structures summarized in the top right of Figs. 6 might be altered so as to have the cobalt capped with one to two $\mathrm{C}$ or $\mathrm{B}$ atoms with a few terminating hydrogens, as indicated in Fig. 7. While the possible variations of these structures are incomplete, enumerating more variations is not a valuable exercise: the sensitivity of the Co $K$-edge XANES to these atomic arrangements is insufficient (as seen in Fig. 7) and improved agreement with experiment is unlikely. We conclude that (among single-site $\mathrm{Co}$ atom arrangements) $\mathrm{Co}-\mathrm{CB}_{10} \mathrm{H}_{x}$ or $\mathrm{Co}-\mathrm{C}_{2} \mathrm{~B}_{9} \mathrm{H}_{y}$ capped with one to two $\mathrm{C}$ or $\mathrm{B}$ 
atoms with few hydrogens provides reasonably good fit to the experimental XANES. Note that while single Co-site based clusters may account for all spectral features observed in the experimental XANES, i.e., $\operatorname{XANES}_{\exp }(E)$ $\sim \mathrm{XANES}_{1}(E)$, this implies that $\mathrm{XANES}_{1}(E) \sim \mathrm{XANES}_{2}(E)$ in Eq. (1). That is to say that the XANES spectra of presumably two nonequivalent Co sites are similar to each other that, in turn, indicates similarities in local atomic structures about $\mathrm{Co}(1)$ and $\mathrm{Co}(2)$ sites.

To build the distinctive structures that satisfy both the EXAFS experimental observations (the $\mathrm{Co}-\mathrm{B}$ interatomic distance of $2.1 \AA$ and the Co-Co interatomic distance of $5.28 \AA$ ) and our XANES results for single-site Co clusters (Fig. 7) implies that at least two icosahedral cages are involved. Limiting ourselves to cluster models with two cages or some cobaltocene and metacarborane nanofragments, there are two distinctive types of structure meeting all the above requirements: two adjoined $\mathrm{CoCB}_{10} \mathrm{H}_{y}$ cages (Fig. 8) or two $\mathrm{CoCB}_{10} \mathrm{H}_{y}$ cages are bridged via few organic $(\mathrm{B}, \mathrm{C}$, and $\mathrm{H}$ ) residual species (not shown). Both models imply that the pairwise Co doping promotes polymerization of the icosahedral cages. Among the many models tested, the structure shown in Fig. 8 gives rise to the model Co $K$-edge XANES spectrum, which is most similar to the experimental XANES spectrum. In analogy to the results presented in Fig. 7, the Co atoms may or may not be capped with one to two $\mathrm{C}$ or $\mathrm{B}$ atoms and with few hydrogens.

The positions of the XANES features, labeled $A_{i}, B, C_{i}$, and $D$ in Fig. 8, can be reasonably explained in terms of single-electron multiple scattering calculations. The intensities of the pre-edge peak at $7709 \mathrm{eV}$ and the $A_{1}$ feature are too large to be in complete agreement with experiment. The $A_{2}$ (at $\sim 7720 \mathrm{eV}$ ) and the $C_{1}$ features (approximately $7 \mathrm{eV}$ above the main peak), that are seen in experiment, are also missed in the model spectrum. The experimental $C_{1}$ feature could be a shake up in origin. ${ }^{36}$

Differences between the cluster model calculations and experiment may be understood from the fact that we have a very low concentration of cobalt in a material with little long-range order. A mixture of similar types of cobalt pairing sites is likely not recovered fully in the model calculations. Many electron effects are also not included. In addition, the non-self-consistent field potentials used, to save computation time, do have a number of limitations. In spite of these considerations, this effort provides a better insight into the local structure of icosahedral boron carbides than previous NEXAFS studies. ${ }^{37,38}$ Unlike some predictions, ${ }^{31}$ the data presented here provide some evidence that the icosahedral cage is preserved in the PECVD grown $\mathrm{C}_{2} \mathrm{~B}_{10} \mathrm{H}_{x}$ semiconducting boron carbides. The pairing of the cobalt atoms, but not in close proximity, suggests a role for strain or extended orbitals. For example, $\mathrm{HgBa}_{2} \mathrm{CuO}_{4}$ seems to involve orbitals that extend beyond third-nearest-neighbor atoms. ${ }^{39}$ The nature of the pairwise interaction of cobalt needs to be determined.

\section{SUMMARY}

Local atomic structure about the $\mathrm{Co}$ atoms in the Codoped PECVD grown " $\mathrm{C}_{2} \mathrm{~B}_{10} \mathrm{H}_{x}$ " semiconducting boron car- bides has been determined from combined Co $K$-edge EXAFS and XANES analyses. EXAFS results indicate that Co has $6 \pm 2$ neighbors at $2.10 \pm 0.02 \AA$ and $2 \pm 1$ neighbors at $1.96 \pm 0.02 \AA$. EXAFS cannot distinguish whether Co is surrounded by boron or carbon atoms. Pairwise Co doping is seen to occur with Co atoms 5.28 $\pm 0.02 \AA$ apart.

First principles Co $K$-edge XANES calculations permit us to recover chemical composition and three dimensional local structure about the Co atoms. The Co atoms are found to be fivefold boron coordinated and are chemically bonded to the icosahedral cages of $\mathrm{B}_{10} \mathrm{CH}_{x}$ or $\mathrm{B}_{9} \mathrm{C}_{2} \mathrm{H}_{y}$, as shown in Fig. 8. This and structurally similar types of cobalt pairing sites (with two icosahedral cages involved) are embedded into the boron carbide matrix. Co $K$-edge XANES and EXAFS are not sensitive enough to the hydrogen atoms and hydrogen location and stoichiometry cannot be reliably determined.

\section{ACKNOWLEDGMENTS}

This work was supported by the Office of Naval Research (Grant No. N00014-06-1-0616) and the Defense Threat Reduction Agency through Grant Nos. MIPR 062310M and HDTRA1-07-1-0008. XANES simulations were conducted at SuperMike, High Performance Computing at LSU. CAMD is supported by the Louisiana Board of Regents. This work was undertaken in partial fulfillment of the degree at AFIT by one of the authors (L.C.). The views expressed in this article are those of the authors and do not reflect the official policy or position of the Air Force, Department of Defense or the U.S. Government. The authors acknowledge a number of helpful conversations with S. Balaz, N. M. Boag, and R. Skomski.

${ }^{1}$ B. W. Robertson, S. Adenwalla, A. Harken, P. Welsch, J. I. Brand, P. A. Dowben, and J. P. Claassen, Appl. Phys. Lett. 80, 3644 (2002).

${ }^{2}$ B. W. Robertson, S. Adenwalla, A. Harken, P. Welsch, J. I. Brand, J. P. Claassen, N. M. Boag, and P. A. Dowben, Proc. SPIE 4785, 226 (2002).

${ }^{3}$ S. Adenwalla, R. Billa, J. I. Brand, E. Day, M. J. Diaz, A. Harken, A. McMullen-Gunn, R. Padmanabhan, and B. W. Robertson, Proc. SPIE 5199, 70 (2003).

${ }^{4}$ A. D. Harken, E. E. Day, B. W. Robertson, and S. Adenwalla, Jpn. J. Appl. Phys., Part 1 44, 444 (2005).

${ }^{5}$ K. Osberg, N. Schemm, S. Balkir, J. I. Brand, S. Hallbeck, P. Dowben, and M. W. Hoffman, IEEE Sens. J. 6, 1531 (2006).

${ }^{6}$ A. N. Caruso, P. A. Dowben, S. Balkir, N. Schemm, K. Osberg, R. W. Fairchild, O. Barrios Flores, S. Balaz, A. D. Harken, B. W. Robertson, and J. I. Brand, Mater. Sci. Eng., B 135, 129 (2006).

${ }^{7}$ A. N. Caruso, R. B. Billa, S. Balaz, J. I. Brand, and P. A. Dowben, J. Phys.: Condens. Matter 16, L139 (2004).

${ }^{8}$ P. Lunca-Popa, J. I. Brand, S. Balaz, L. G. Rosa, N. M. Boag, M. Bai, B. W. Robertson, and P. A. Dowben, J. Phys. D 38, 1248 (2005).

${ }^{9}$ H. Takizawa, N. Haze, K. Okamoto, K. Uheda, and T. Endo, Mater. Res. Bull. 37, 113 (2002).

${ }^{10}$ U. Kuhlmann, H. Werheit, J. Pelloth, W. Keune, and T. Lundstrom, Phys. Status Solidi B 187, 43 (1995).

${ }^{11}$ U. Kuhlmann, H. Werheit, T. Dose, and T. Lundstrom, J. Alloys Compd. 186, 187 (1992).

${ }^{12}$ T. Nakayama and K. Kimura, J. Jpn. Inst. Met. 63, 1400 (1999).

${ }^{13}$ H. Werheit, R. Schmechel, V. Kueffel, and T. Lundstrom, J. Alloys Compd. 262, 372 (1997).

${ }^{14}$ S.-D. Hwang, K. Yang, P. A. Dowben, A. A. Ahmad, N. J. Ianno, J. Z. Li, J. Y. Lin, H. X. Jiang, and D. N. McIlroy, Appl. Phys. Lett. 70, 1028 (1997).

${ }^{15}$ D. N. McIlroy, S.-D. Hwang, K. Yang, N. Remmes, P. A. Dowben, A. A. Ahmad, N. J. Ianno, J. Z. Li, J. Y. Lin, and H. X. Jiang, Appl. Phys. A: 
Mater. Sci. Process. 67, 335 (1998).

${ }^{16}$ S.-D. Hwang, N. B. Remmes, P. A. Dowben, and D. N. McIlroy, J. Vac. Sci. Technol. B 14, 2957 (1996).

${ }^{17}$ S.-D. Hwang, N. Remmes, P. A. Dowben, and D. N. McIlroy, J. Vac. Sci. Technol. A 15, 854 (1997)

${ }^{18}$ L. Carlson, D. LaGraffe, S. Balaz, A. Ignatov, Ya. B. Losovyj, J. Choi, P. A. Dowben, and J. I. Brand, Appl. Phys. A: Mater. Sci. Process. 89, 195 (2007).

${ }^{19} \mathrm{H}$. Werheit, in Numerical Data and Functional Relationships in Science and Technology, edited by O. Madelung, Landolt-Börnstein, New Series, Group III, Vol. 41D (Springer, Berlin, 2000), pp. 1-491, and references therein.

${ }^{20}$ C. C. Ilie, S. Balaz, L. G. Rosa, J. Zhang, P. Lunca-Popa, C. Bianchetti, R. Tittsworth, J. I. Brand, B. Doudin, and P. A. Dowben, Appl. Phys. A Mater. Sci. Process. 81, 1613 (2005).

${ }^{21}$ S. Balaz, D. I. Dimov, N. M. Boag, K. Nelson, B. Montag, J. I. Brand, and P. A. Dowben, Appl. Phys. A: Mater. Sci. Process. 84, 149 (2006).

${ }^{22}$ S. A. Chambers, T. C. Droubay, C. M. Wang, K. M. Rosso, S. M. Heald, D. A. Schwartz, K. R. Kittilstved, and D. R. Gamelin, Mater. Today 9, 28 (2006).

${ }^{23}$ S. A. Chambers, Surf. Sci. Rep. 61, 345 (2006)

${ }^{24}$ T. C. Kaspar, T. Droubay, D. E. McCready, P. Nachimuthu, S. M. Heald, C. M. Wang, A. S. Lea, V. Shutthanandan, S. A. Chambers, and M. F. Toney, J. Vac. Sci. Technol. B 24, 2012 (2006); S. A. Chambers, T. Droubay, C. M. Wang, A. S. Lea, R. F. C. Farrow, L. Folks, V. Deline, and S. Anders, Appl. Phys. Lett. 82, 1257 (2003); H. Q. Song, L. M. Mei, S. S. Yan, X. L. Ma, J. P. Liu, Y. Wang, and Z. Zhang, J. Appl. Phys. 99, 123903 (2006); G. S. Chang, E. Z. Kurmaev, D. W. Boukhvalov, D. L. Finkelstein, D. H. Kim, T. W. Noh, A. Moewes, and T. A. Callcott, J. Phys.: Condens. Matter 18, 4243 (2006); B. S. Jeong, Y. W. Heo, D. P.
Norton, and A. F. Hebard, Physica B 370, 46 (2005).

${ }^{25}$ C. A. Formstone, E. T. FitzGerald, P. A. Cox, and D. O'Hare, Inorg. Chem. 29, 3860 (1990).

${ }^{26}$ L. Hernán, J. Morales, L. Sánchez, J. Santos, J. P. Espinós, A. R. González-Elipe, and J. P. Holgado, Surf. Sci. 477, L295 (2001).

${ }^{27}$ M. Lemonnier, O. Collet, C. Depautex, J. M. Esteva, and D. Raoux, Nucl. Instrum. Methods 152, 109 (1978).

${ }^{28}$ T. M. Hayes and J. B. Boyce, in Solid State Physics, edited by H. Ehrenreich, F. Seitz, and D. Turnbull (Academic, New York, 1982), Vol. 37, p. 173 .

${ }^{29}$ A. L. Ankudinov, B. Ravel, J. J. Rehr, and S. D. Conradson, Phys. Rev. B 58, 7565 (1998).

${ }^{30}$ A. Yu. Ignatov (unpublished); P. J. Durham, J. B. Pendry, and C. H. Hodges, Comput. Phys. Commun. 25, 193 (1982).

${ }^{31}$ K. Park, M. R. Pederson, L. L. Boyer, W. N. Mei, R. F. Sabirianov, X. C. Zeng, S. Bulusu, S. Curran, J. Dewald, E. Day, S. Adenwalla, M. Diaz, L. G. Rosa, S. Balaz, and P. A. Dowben, Phys. Rev. B 73, 035109 (2006).

${ }^{32}$ D.-Q. Feng, J. Liu, A. P. Hitchcock, A. L. D. Kilcoyne, T. Tyliszczak, E. Rühl, J. D. Bozek, and P. A. Dowben (unpublished).

${ }^{33}$ M. F. Hawthorne, Acc. Chem. Res. 1, 281 (1968).

${ }^{34}$ R. B. King, Chem. Rev. (Washington, D.C.) 101, 1119 (2001).

${ }^{35}$ S. Balaz, A. N. Caruso, N. P. Platt, D. I. Dimov, N. M. Boag, J. I. Brand, Ya. B. Losovyj, and P. A. Dowben, J. Phys. Chem. B 111, 7009 (2007).

${ }^{36}$ A. Yu. Ignatov, N. Ali, and S. Khalid, Phys. Rev. B 64, 014413 (2001).

${ }^{37}$ S. W. Lee, J. Mazurowski, W. L. Obrien, Q. Y. Dong, J. J. Jia, T. A. Callcott, Y. X. Tan, K. E. Miyano, D. L. Ederer, D. R. Mueller, and P. A. Dowben, J. Appl. Phys. 74, 6919 (1993).

${ }^{38}$ I. Jiménez, D. G. J. Sutherland, T. van Buuren, J. A. Carlisle, L. J. Terminello, and F. J. Himpsel, Phys. Rev. B 57, 13167 (1998).

${ }^{39}$ O. K. Andersen and T. Saha-Dasgupta, Phys. Rev. B 62, R16219 (2000). 